\title{
COMMENT
}

\section{Global pediatric research investigator}

\author{
Zeinab Anwar El-Kabbany ${ }^{1}$ \\ Pediatric Research (2020) 87:8; https://doi.org/10.1038/s41390-019-0640-0
}

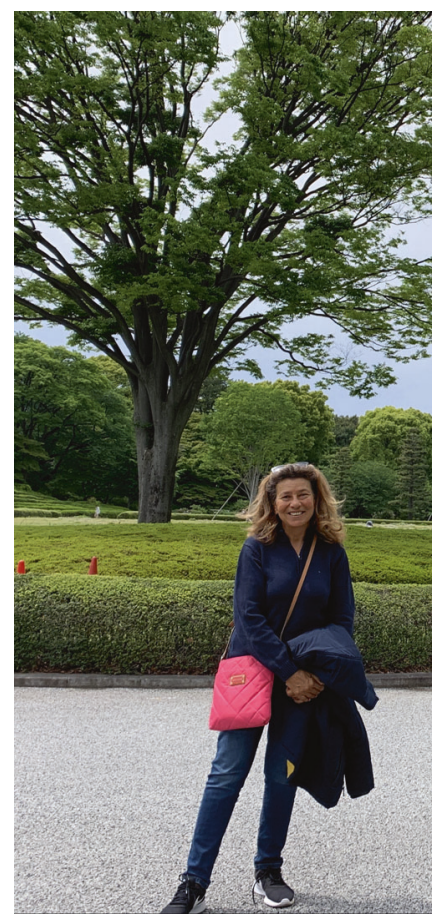

I was born and brought up in Cairo, Egypt. I received my primary, preparatory, and secondary education at English Mission Language School, where I was taught discipline, honesty, self-respect, respect for others, and modesty, and that loving your work and spending as much effort as you can on everything you do will help fulfill your wishes and goals.

I am very keen on properly organizing my time, and I believe in the proverb "early to bed and early to rise make one healthy, wealthy, and wise." I wake up very early and enjoy swimming before going to work, which improves my mood, health, and well-being and helps me begin my day with optimism.

I adore listening to music, which brightens my life and makes me very happy, especially while jogging. My favorite pieces are those by Chopin, Mozart, and Beethoven. I love nature, and I travel often to enjoy the different faces of Mother Nature.

Throughout my life, I have loved children and enjoyed communicating with them. A smile on a child's face thrills me. It touches me deeply to see a child in agony or suffering, which is why I chose the field of pediatrics-to help relieve children's pain. My happiest hours are those that I spend among my patients. It gives me great self-satisfaction to be able to reach the proper diagnosis for a patient and to offer him or her the right treatment. My fields of interest are pediatric and neonatal hepatology, hepatoendocrinology, nutrition and obesity, metabolism and inborn errors of metabolism, and genetic disorders.

I love teaching, and it pleases me greatly to be able to convey my knowledge and experience to younger generations. I have served as a professor of pediatrics on the Faculty of Medicine at Ain Shams University in Cairo, Egypt, since 1998. I am a former head of the hepatology, neonatology, and nutrition units of the Children's Hospital at Ain Shams University. I have co-supervised over 100 master's and doctoral pediatric theses.

I have presented at over 100 international, regional, and local congresses and published more than 100 scientific publications in local and international periodicals. I serve as an honorary consultant for pediatric hepatology and nutrition at Ain Shams University Hospital.

In addition, I am a reviewer for several peer-reviewed international and regional journals and have received several awards from the Egyptian Syndicate for international publications. I am a member of the Egyptian Society of Pediatrics, the Egyptian Pediatrics Association, the Egyptian Association for the Study of Gastrointestinal Nutritional and Liver Diseases, the American Association for the Study of Liver Diseases, and the European Association for the Study of the Liver.

\section{ADDITIONAL INFORMATION}

Competing interests: The author declares no competing interests.

Publisher's note Springer Nature remains neutral with regard to jurisdictional claims in published maps and institutional affiliations. 